\title{
Full-depth avalanche occurrences caused by snow gliding, Coquihalla, British Columbia, Canada
}

\author{
Jennifer Clarke, ${ }^{1}$ David MaGlung ${ }^{2}$ \\ ${ }^{1}$ EBA Engineering Consultants Ltd, Suite 550, 1100 Melville Street, Vancouver, British Columbia V6E 4A6, Canada \\ ${ }^{2}$ University of British Columbia, Department of Geography, 1984 West Mall, Vancouver, British Columbia V6T 122, Canada
}

\begin{abstract}
Snow glide is the translational slip of the entire snowpack over a sloping ground surface, and it is thought that rapid rates of snow glide precede full-depth avalanches. The nature of avalanches that release at the ground makes them difficult to predict and difficult to control using explosives.

On-slope instrumentation comprised of stainless-steel "glide shoes" was used to measure rates of snow glide for two winters on a bedrock slope adjacent to the Coquihalla Highway, Cascade Mountains, British Columbia, Canada. Climate data and avalanche occurrences were recorded by the British Columbia Ministry of Transportation and Highways.

Our results show that the supply of free water to the snow/ground interface by rain or snowmelt is the most important influence on full-depth avalanche release. Full-depth avalanche release responds to rainfall and snowmelt events within 12-24 hours. Occasionally, full-depth avalanches occur unexpectedly during clear, cold periods. Snowmelt by radiation is thought to contribute enough meltwater during these cold periods to induce higher rates of snow glide and full-depth avalanche release. The results also indicate that snow glide alone is not a reliable indicator for full-depth avalanche release.
\end{abstract}

\section{INTRODUGTION}

Full-depth avalanches, where the entire snowpack down to the ground is mobilized, are unpredictable and dangerous due to the great mass of snow involved. The process of snow glide has always been associated with the release of avalanches of this type, which are also called glide avalanches. The mechanics of full-depth avalanche initiation by gliding has been described by Lackinger (1987) and McClung (1987). A tensile fracture, or glide crack, forms in the snowpack, initiated by rapid gliding (McClung and Schaerer, 1993). Formation of this fracture generally requires an increase in glide speed (reduction in boundary friction) downslope from the tensile fracture.

Full-depth avalanches are also commonly associated with wet, seasonal snowpacks. Due to the different mechanical properties between wet and dry snow, large amounts of energy are required to propagate shear fractures for failure in wet snow, often making full-depth avalanches difficult to trigger using explosives. Full-depth avalanche forecasting, therefore, has typically been beyond the norm of traditional techniques. In this paper, we investigate the processes and mechanisms contributing to full-depth avalanche release.

Early investigations of snow glide were primarily descriptive (In der Gand and Zupančic, 1966). Later studies characterized the mechanics of snow glide. Prerequisites for the onset of gliding, formulated from field observations (McClung, 1975, 1981), are:

(1) a fairly smooth snow/ground interface such as bare rock or grassy vegetation. The interface is more difficult to define in rough (i.e. brushy) terrain;

(2) a snow/ground interface at $0{ }^{\circ} \mathrm{C}$ which allows for the presence of free water, a necessary factor for snow glide; and

(3) a slope greater than $15^{\circ}$ for roughness typical of alpine terrain (i.e. bare rock or brushy terrain).

Currently, we know of no studies in which investigations of the direct effect of meteorological conditions on rates of glide and full-depth avalanche release were conducted on a continuous basis. Lackinger (1987) presented glide rates and the associated climate prior to a full-depth avalanche release, but since his instrumentation was placed on the avalanche slope, data collection ceased after the first avalanche. In the study we present here, continuously recorded rates of snow glide are used to identify predictive factors and their relation to avalanche release on adjacent slopes in the study area.

Our objectives were:

to examine the effect of free-water contributions on rates of snow glide and full-depth avalanche release;

to determine the relative importance of contributions from rainfall and snowmelt to glide; and

to investigate the relationship between rapid rates of snow glide, climate conditions and the release of fulldepth avalanches.

\section{METHODS}

\subsection{Study area}

The study area is located on Yak Peak and Zopkios Ridge 
adjacent to the Coquihalla Highway in the Cascade Mountains of southern British Columbia, Canada, approximately $250 \mathrm{~km}$ east of Vancouver (Fig. 1). The study site, characterized by smooth, south-facing granite slopes, is exposed to incoming solar radiation throughout the year, which moderates air and snow temperatures.

The area has a maritime winter climate that is characterized by heavy snowfalls and mild temperatures. Annual average winter precipitation (October-May) measured between 1973 and 1978 at the Summit Weather Station (1230 m a.s.l.) was $1293 \mathrm{~mm}$ (British Columbia Ministry of Environment, 1985). In $1992-93$ and 1993-94, winter precipitation measured between November and April by the British Columbia Ministry of Transportation and Highways (MOTH) at the same station was 801 and $1011 \mathrm{~mm}$, respectively. Rain comprises about one-third of the winter precipitation total at the Summit Weather Station.

\subsection{Avalanches in the study area}

There are 108 avalanche paths in the Coquihalla avalanche area identified by MOTH, of which 67 affect $17 \mathrm{~km}$ of the highway. Full-depth avalanches frequently occur on at least ten of these avalanche paths along the highway. Terrain characteristics, when combined with moist snowpack conditions, create an optimal situation for full-depth avalanches, making this an ideal and unique study site.

Avalanches occurring on nine similar paths known to produce full-depth avalanches were chosen for this study.

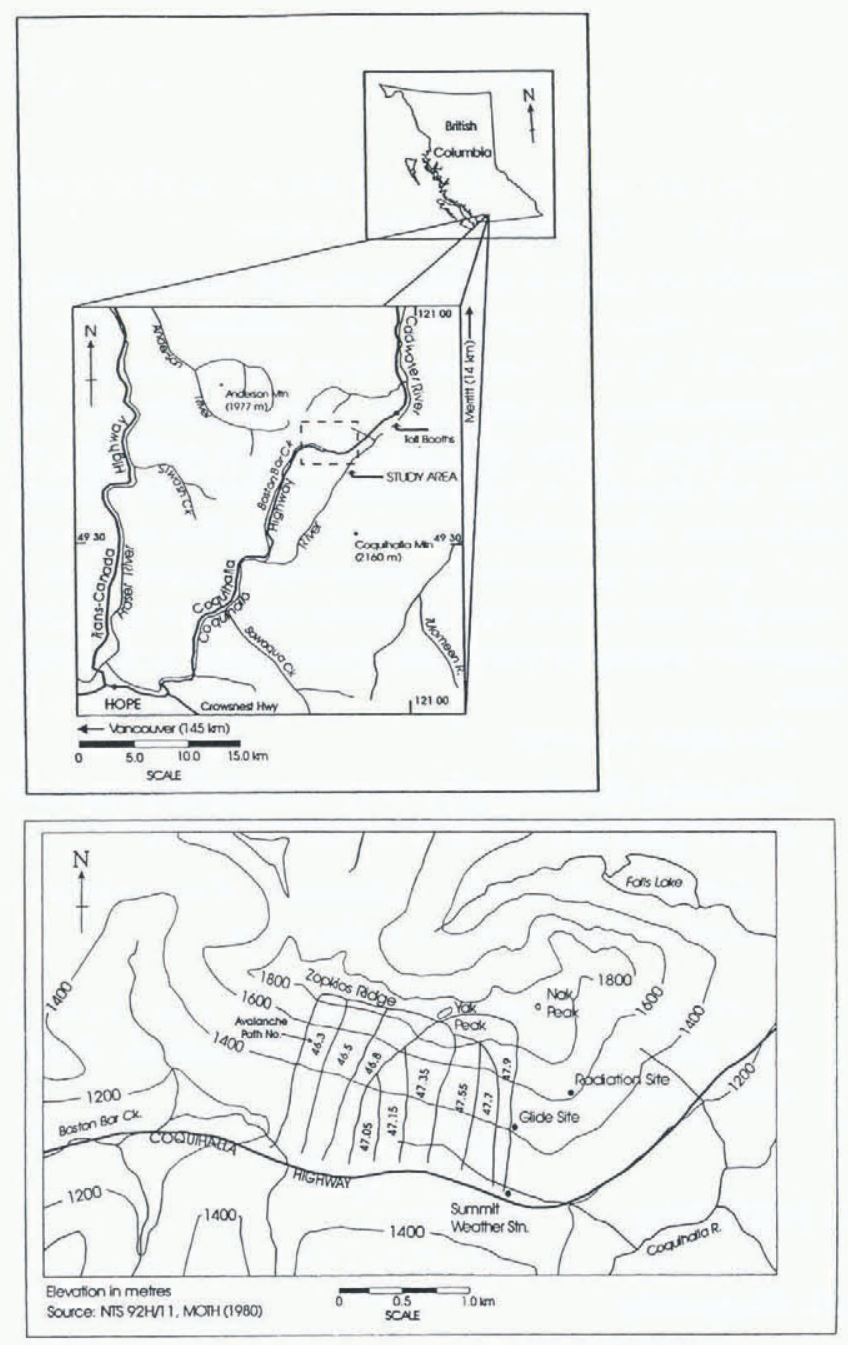

Fig. 1. Location of the study area.

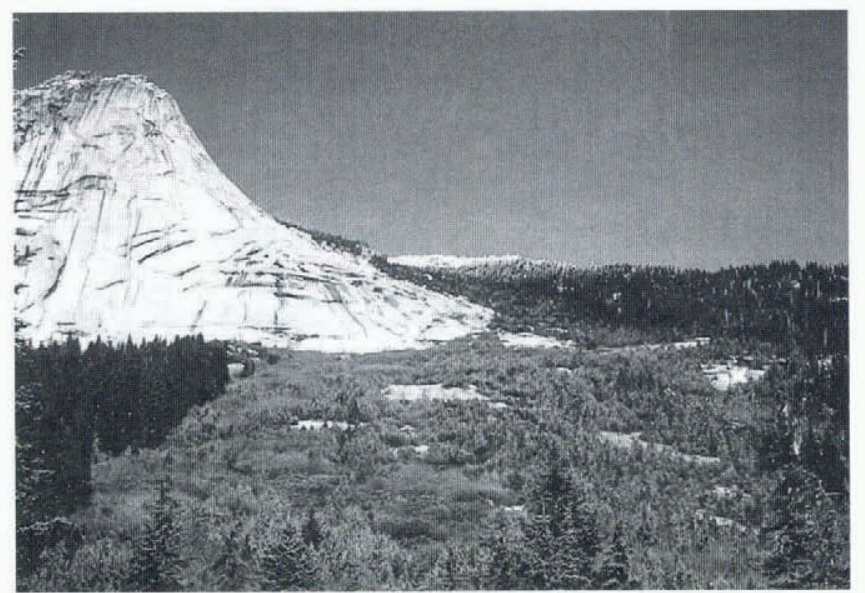

Fig. 2. Smooth granite slopes of Zopkios Ridge; glide site on right. Glide site, on right side of photo, is indicated with an " $x$ ".

They were all situated on Zopkios Ridge (Fig. 1). All paths have very similar relief $(1250 \mathrm{~m})$. All starting zones are located on smooth granite with inclinations of 34-46 . Avalanche tracks vary from $24^{\circ}$ to $32^{\circ}$, and run-out lengths reach at least as far as the highway situated at the valley bottom. Figure 2 illustrates the smooth granite slopes that characterize the study site.

Full-depth avalanches form a significant proportion of all naturally occurring avalanches in the study area as observed by MOTH avalanche technicians. From the characteristics of each slide recorded by the technicians, the following were used to identify full-depth avalanche occurrences: release level at the ground; moist to wet avalanche deposits; and start locations at the top to the middle of the avalanche path, where bare bedrock surfaces generally prevail.

\subsection{Snow-glide instrumentation and measurement}

In der Gand and Zupančic (1966) first developed snow-glide instrumentation, upon which installations for this study were based. Measurements at our study site were first established by D. McClung in 1987 using the same instrumentation, and some preliminary observations have been published (see McClung and others, 1994).

Snow glide was measured by placing flat-bottomed stainless-steel boxes with inner baffles on the rock surface at the beginning of the season. These boxes, or "glide shoes", were open at the top so that snow could fall into them. Oriented downslope, the glide shoes were fastened to recording potentiometers with strong cord. The potentiometers were housed in weatherproof enclosures, sheltered in excavated bedrock and covered with a steel plate. Figure 3 illustrates typical instrumentation set-up at the time of installation in late fall. Downslope displacement and temperatures (air, ground and interface) were recorded on a data logger at the site and downloaded via modem. The data logger was powered by a $12 \mathrm{~V}$ battery and solar panels.

Snow-glide instrumentation was installed adjacent to path No. 47.9 at $1450 \mathrm{~m}$ a.s.l. (see Fig. 1). The site is characterized by the same bare granite as adjacent slopes and is steep enough for gliding $\left(31^{\circ}\right)$ but barely steep enough for avalanches. Thus, measurements may be obtained for the duration of the season. In addition, vegetation at the top and on either side of the site intercepts water and increases the local area roughness enough to reduce the potential for avalanches. The glide site is just visible on the right side of the 


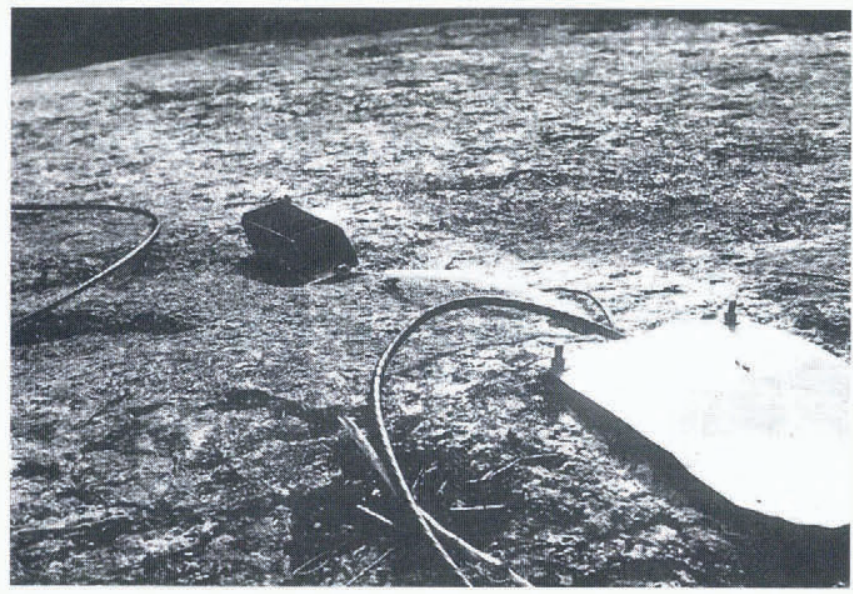

Fig. 3. Typical glide-shoe set-up at time of installation. Potentiometer is housed in a weatherproof enclosure and placed in rock cavity beneath a steel plate.

photo shown in Figure 2, and site conditions (shown prior to instrument installation) are illustrated in Figure 4.

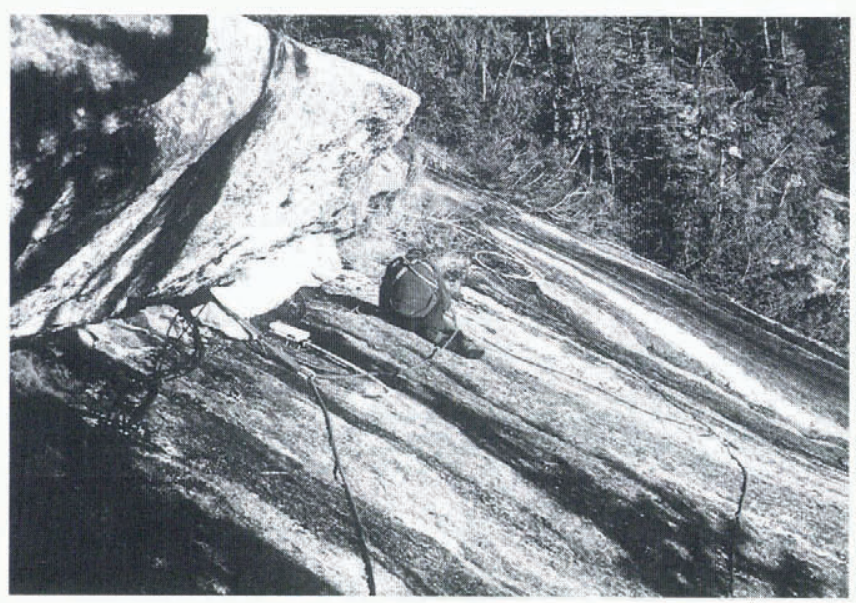

Fig. 4. Glide site at time of instrument set-up in late fall. Note water paths on rock surface.

Five glide shoes were placed across the slope, as shown in Figure 5, providing measurements of snow glide across and down the slope with respect to a jointed step in the granite bedrock. Instrumented snow glide at the site is considered a surrogate for conditions on upper slopes and on adjacent slopes of Zopkios Ridge.

\subsection{Snow pack characterization}

Snowpack conditions were continuously recorded at the study site and were also recorded during periodic visits to the field site. The frequency of the visits was determined by avalanche hazard conditions in the area.

Thermistors were placed at the snowpack interface and within the ground (depth $1 \mathrm{~cm}$ ) to monitor snow/ground-interface and ground temperatures. Air temperatures at the site were also recorded.

Volumetric water content of the snow was measured using a snow-wetness sensor (Denoth, 1994) that measures dielectric permittivity.

\section{THEORETICAL BACKGROUND}

\subsection{Snow-glide mechanics}

The snow-glide model developed by McClung and Clarke
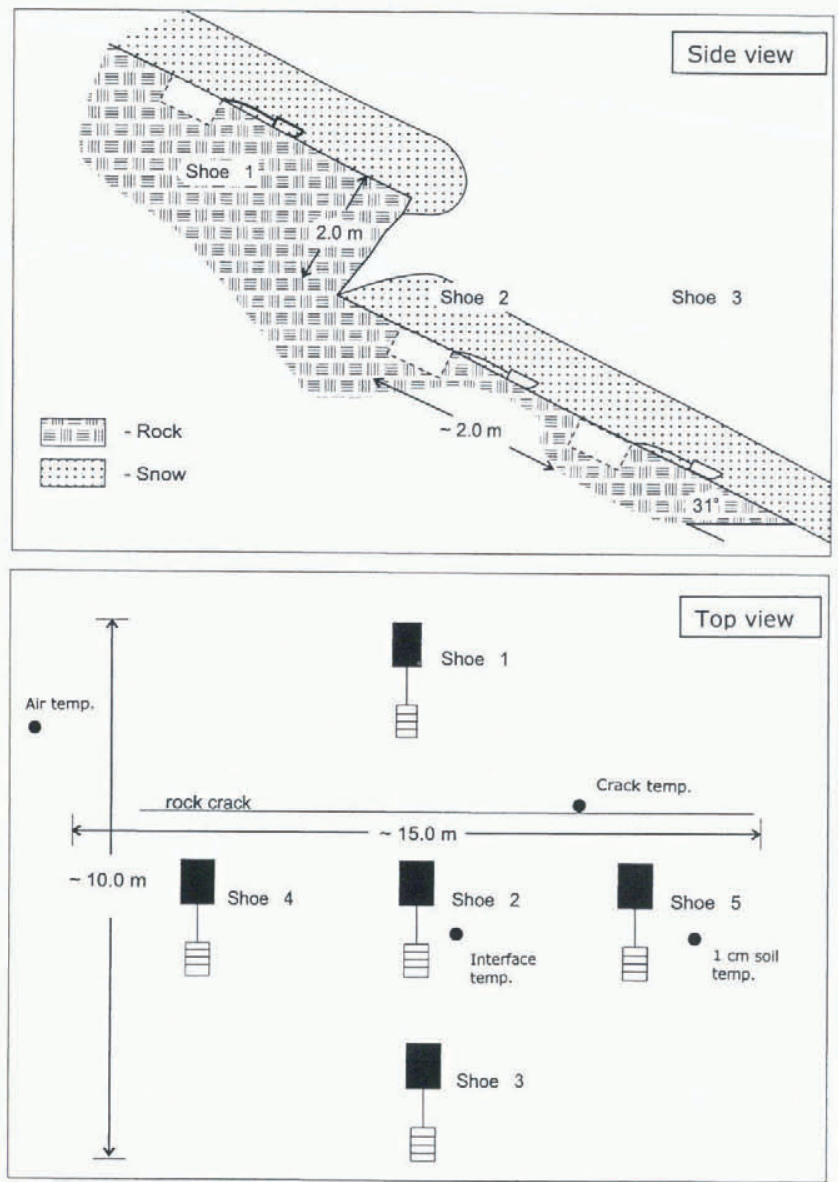

Note: Schematic drawing - not to scale

Fig. 5. Placement of glide shoes.

(1987) suggests that water in the snowpack - both the thickness of the water layer at the snow-rock interface and the wetness of the snow itself - is the most critical parameter in determining glide and full-depth avalanches. In the McClung and Clarke model, it is assumed that snow properties are free of longitudinal gradients, that there is a uniform planar slope and that the snow deforms as a linear, viscous material. The constitutive equation relating the tangential drag on the snowpack, or local basal shear stress, $\tau$, to the glide velocity, $U_{\mathrm{o}}$, is:

$$
\tau=\frac{\mu U_{\mathrm{o}}}{2(1-v) D^{*}},
$$

where $D^{*}$ is the stagnation depth and $\mu$ and $v$ are the shear viscosity and viscous Poisson ratio of snow above the interface. In general, $D^{*}$ is a function of interface geometry and water distribution at the interface, and its geometric construction is illustrated in Figure 6. The stagnation-depth parameter incorporates changes in friction conditions at the interface due to variations in free water at the interface and in interaction with interface roughness features. The shear viscosity and viscous Poisson ratio are influenced by changing density and by changing water contents in the snow pack (McClung and Clarke, 1987).

McClung and Clarke (1987) indicate that changing friction conditions at the snow/ground interface and changes in viscosity of the snow above the interface explain fluctuations in glide velocity. Both are sensitive to the presence of water.

Water at the snow/ground interface may drown out some of the small roughness features leading to conditions of snowpack separation. McClung and Clarke (1987) show that there is an exponential increase in glide speed (glide gain) with a 


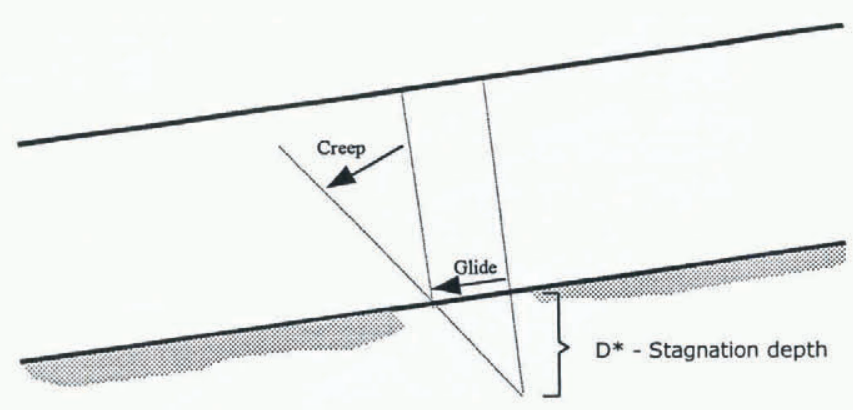

Fig. 6. Schematic distinguishing between snow creep and glide showing the geometrical construction of stagnation depth (D) (after Nye, 1969).

linear increase in water-layer thickness for a specific geometry. The enhancement of glide rates is presumed to depend not only on the water thickness but also on the location of the separation and contact points (Lliboutry, 1968), which makes the area of coverage more important than the thickness.

Tensile fractures, called glide cracks, form perpendicular to the ground surface (McClung, 1987) and develop at the crest of an avalanche. During glide-crack formation, rates of snow glide are high (Endo, 1983) and increase downslope from a glide crack, indicating a longitudinal glide gradient (Yamada and others, 1991; McClung and Schaerer, 1993). Glide cracks precede full-depth avalanches, but avalanche release does not always immediately follow glide-crack formation. The stability of the snowpack after crack formation depends on interface topography and friction conditions.

It is thought that intervals of rapid gliding precede, or signal, the release of full-depth avalanches, but no threshold rate or predictive equation has been proposed. Studies by Lackinger (1987) showed that an increase in the frequency and magnitude of micro-seismic emissions signaled the impending release of a full-depth avalanche approximately 3 hours prior to the event. The increase in seismic emissions may have been caused by increased glide velocity.

\section{OBSERVATIONS}

\subsection{Snow and meteorological conditions}

At our study site, thermistors placed at the snow/ground interface indicate that temperatures were at $0^{\circ} \mathrm{C}$ throughout two study seasons. Snow-profile observations indicated that snow grains at the base of the snowpack reached an equilibrium diameter of 1.0-2.0 mm, with free-water contents of $6-14 \%$ (by volume) (Table 1). As a result, there was always a thin film of slushy wet snow adjacent to the interface. Snow- hardness measurements at the study site indicate that this slushy layer was overlain by hard dry snow (Table 1).

\subsection{Snow-glide characteristics at the study site}

Mean monthly glide rates for glide shoes placed across the study slope are summarized in Table 2. In 1992-93, glide rates were lower and there were fewer full-depth avalanches (26) than in the 1993-94 season (78). Figure 7a and b show glide velocities, derived from displacements of glide-shoe instruments, in $\mathrm{mm} \mathrm{d}^{-1}$ for every 12 hour time period.

Observations indicate that early in the winter season, summer heat storage in underlying rock, thin snowpacks and relatively low snow densities contribute to high glide rates. At the end of the season, in the spring, meltwater and an increased frequency of rain-on-snow events contribute to peaks in snow glide. More consistent glide rates are common throughout mid-winter periods, indicating a colder, stiffer snow pack.

Regression analysis of accumulated glide over 12 hour time periods, daytime $(0600-1800 \mathrm{~h})$ and night-time $(1800-0600 \mathrm{~h})$, for the entire length of the study confirms observations by McClung and others (1994) that there is little distinction between day- and night-time rates of snow glide (Clarke, 1994).

\subsection{Full-depth avalanche occurrences}

Fifty-one per cent of avalanches in the study area were fulldepth in 1992-93, and 85\% of the occurrences in 1993-94. The frequency of suspected full-depth avalanche trigger

Table 1. Conditions at the snow/ground interface (Coquihalla glide site)

\begin{tabular}{lcccccc}
\hline \multicolumn{1}{c}{ Date } & $\begin{array}{c}\text { Thickness } \\
\text { of sat. } \\
\text { layer }\end{array}$ & $\begin{array}{c}\text { Grain } \\
\text {-size }\end{array}$ & Temp. & Density ${ }^{1}$ & $\begin{array}{c}\text { Water } \\
\text { content }^{2}\end{array}$ & \\
& $\mathrm{~cm}$ & $\mathrm{~mm}$ & ${ }^{\circ} \mathrm{C}$ & $\mathrm{kg} \mathrm{m}^{-3}$ & $\begin{array}{c}\text { \% by } \\
\text { vol. }\end{array}$ & \\
& & & & & & \\
& & & & & & \\
\hline 16 January 1993 & 1.0 & 0.5 & 0 & 340 & - & $\mathrm{P}$ \\
28 March 1993 & 2.0 & 1.0 & 0 & 480 & 6.47 & $4 \mathrm{~F}$ \\
30 January 1994 & 1.0 & 1.0 & 0 & 380 & 11.2 & $\mathrm{P}$ \\
9 February 1994 & 10.0 & 1.0 & 0 & 500 & 13.5 & $\mathrm{P}$ \\
6 March 1994 & 0.5 & 2.0 & 0 & 370 & 9.6 & $\mathrm{P}$ \\
\hline
\end{tabular}

${ }^{1}$ Average of bottom $10 \mathrm{~cm}$ due to size of sampling tube $(500 \mathrm{~g})$.

${ }^{2}$ Free-water content of snow measured using a dielectric meter.

${ }^{3}$ International Commission on Snow and Ice classification of seasonal snow (Colbeck and others, 1990).

Table 2. Summary of mean glide rates ( $\mathrm{mm} \mathrm{d}^{\prime}$ ), 1992-93 and 1993-94

\begin{tabular}{|c|c|c|c|c|c|c|c|c|c|c|}
\hline & Shoe 1 & Shoe 2 & $\begin{array}{c}199293 \\
\text { Shoe } 4\end{array}$ & Shoe 5 & Avg. & Shoe 1 & Shoe 2 & $\begin{array}{c}199394 \\
\text { Shoe } 4\end{array}$ & Shoe 5 & Avg. \\
\hline November & 13.0 & 8.9 & 18.0 & 17.0 & 14.2 & 18.2 & 13.4 & 27.2 & 25.6 & 21.6 \\
\hline December & 6.0 & 5.3 & 7.8 & 11.0 & 7.5 & 3.5 & 11.0 & 15.2 & 15.5 & 11.5 \\
\hline January & 3.4 & 1.0 & 9.4 & 6.9 & 5.2 & 5.4 & 15.0 & 21.4 & 20.6 & 15.9 \\
\hline March & 1.9 & 6.6 & 6.9 & 1.5 & 4.2 & 3.8 & 15.0 & 38.6 & - & 19.0 \\
\hline April & 2.4 & 9.3 & 21.5 & - & 11.1 & 2.3 & 4.9 & 10.3 & - & 5.0 \\
\hline Average & 4.8 & 6.0 & 11.6 & 9.2 & & 5.7 & 10.5 & 19.7 & 17.3 & \\
\hline
\end{tabular}


mechanisms is listed in Table 3 for both seasons. Our observations show that most full-depth avalanches were probably triggered after the input of liquid water from rain or snowmelt.

Table 3. Full-depth avalanche trigger mechanisms in the study area

\begin{tabular}{lcc}
\hline \multicolumn{1}{c}{ Trigger mechanism } & 1992.93 & $1993-94$ \\
\hline Loading (new snow only) & $3(11.5 \%)$ & $3(3.8 \%)$ \\
Rain-on-snow events & $8(30.8 \%)$ & $54(69.2 \%)$ \\
Snowmelt & $15(57.7 \%)$ & $21(26.9 \%)$ \\
Total & 26 & 78 \\
\hline
\end{tabular}

\section{CORRELATION OF SNOW GLIDE AND FULL- DEPTH AVALANCHE RELEASE}

The correlatation between snow glide and full-depth avalanches is shown in Figure $7 \mathrm{a}$ and $\mathrm{b}$ for two winter seasons. During the 1992-93 winter season, full-depth avalanches were generally triggered when glide rates exceeded $10 \mathrm{~mm} \mathrm{~d}^{-1}$. In the 1993-94 season, avalanches were triggered when rates exceeded $15 \mathrm{~mm} \mathrm{~d}^{-1}$. The results indicate that there is no clear direct relationship between glide rates and full-depth avalanche occurrence.

The record shows that avalanche release sometimes occurs prior to peaks in glide velocity. Increasing rates of glide indicate times of accelerated motion prior to avalanche release, suggesting that changes in friction conditions occur faster than the snowpack can adjust to them. It could be that the best correlation between glide and fulldepth avalanche is during periods of glide acceleration, although this has yet to be fully investigated.

Rates vary between instrumented locations on the slope. In the case shown in Figure $7 b$, rates at shoe 4 are higher
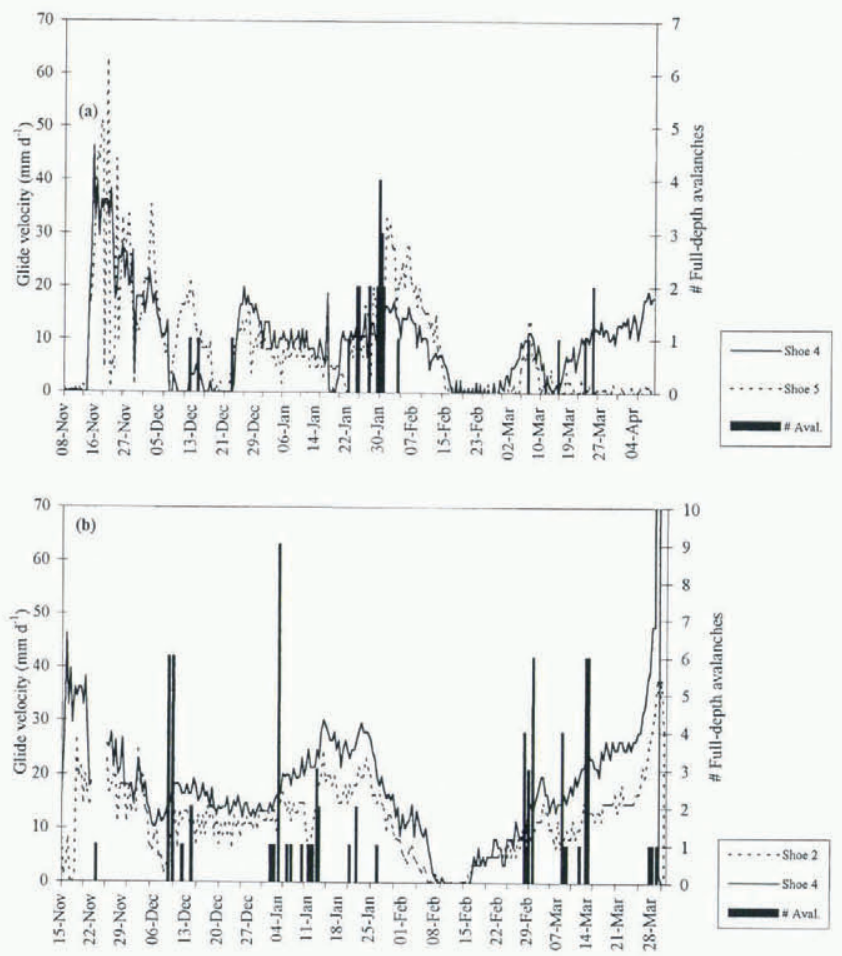

Fig. 7. Full-depth avalanche release and glide rates for (a) 1992-93 season, (b) 1993-94 season. than at shoe 2. This indicates spatial variability of snow glide across the instrumented site. Placement with respect to water-flow patterns visible during the summer and fall is thought to account for some of the differences.

Due to varying glide rates across the slope, a threshold glide rate cannot be specifically determined from the existing dataset. By itself, snow glide instrumented at a site away from avalanche initiation zones is unable to pinpoint times of full-depth avalanche release.

\section{CORRELATION OF FULL-DEPTH AVALANCHE RELEASE AND RAIN-ON-SNOW EVENTS}

Rain-on-snow events, common in the study area during the winter, have a significant effect on glide rates and full-depth avalanche release. During the 1992-93 season, 8 out of 26 full-depth avalanche occurrences are thought to have been triggered by rain-on-snow events and in 1993-94, 54 out of 78 occurrences. Rain contributes free water directly to the snow surface and, where the snowpack thins to bare rock on the upper slopes, directly to the snow/ground interface.

Time-series analysis using cross-correlation was used to compare the distribution of full-depth avalanches and rainfall. The results indicate that for selected "active" time periods there is a strong positive correlation between the two variables (Table 4). Active time periods are defined as periods greater than 1 day, over which there was more than one avalanche event. Results show that full-depth avalanches respond to rain-on-snow events within 12 hours and for up to 48 hours. Delays between rainfall and avalanche release depend on factors such as snow stratigraphy, spatial distribution of bare rock surfaces and the rate of precipitation.

Table 4. Correlation of avalanche occurrence with rain events for selected time periods

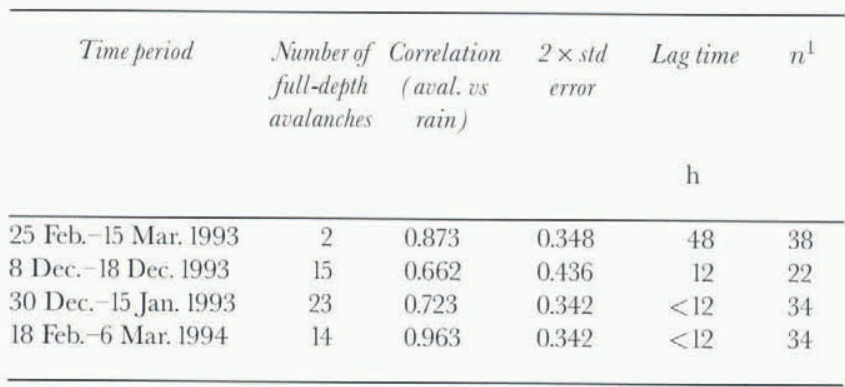

${ }^{1}$ Number of 12 hour periods used in analysis.

The response of glide and avalanche release to rain-onsnow events may be illustrated by discussing several cases. On 9 and 10 December 1993, 12 full-depth avalanches released within 12 hours of $37 \mathrm{~mm}$ of rainfall (Fig. 8). Glide rates during this time were relatively high for all glide shoes (Fig. 8a). The results show that peaks in glide rates occur shortly after avalanche release (i.e. within one 12 hour time period). Avalanches on 12 and 14 December may have released due to the mild, above freezing, temperatures and the introduction of more water into the snowpack.

Figure 9 illustrates conditions for a period during which $81 \mathrm{~mm}$ of rain fell in 48 hours from 28 February to 2 March. A total of 14 full-depth avalanches were released in the same 48 hour period. Glide rates at shoes 2 and 4 increased in response to rainfall and warm temperatures and peaked 2448 hours after avalanche release. The data in Figure 9 show that a significant snowfall event ( $36 \mathrm{~mm}$ w.e.) on 23 Febru- 

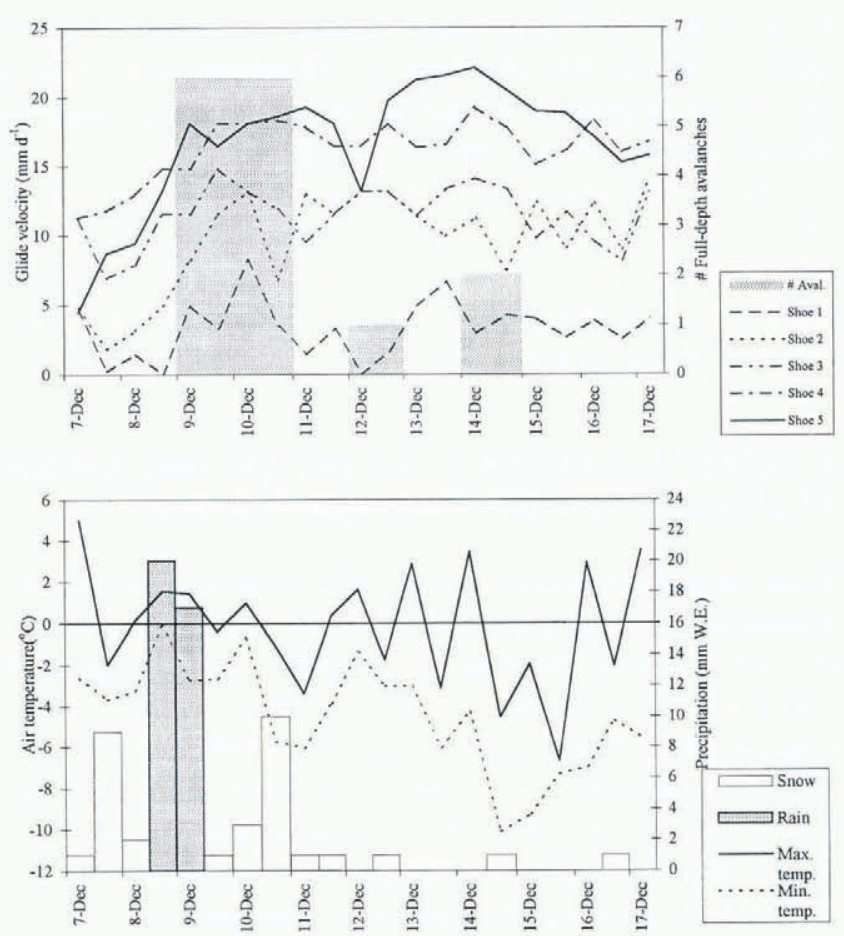

Fig. 8. Full-depth avalanche release by rain-on-snow, 7-17 December 1993.

ary did not trigger any full-depth avalanches, nor did it cause a noticeable increase in glide rates.

Our results indicate that there is a direct relationship between rainfall and full-depth avalanche occurrence. Higher rainfall intensities $\left(\mathrm{mm} \mathrm{h}^{-1}\right)$ correspond with a greater number of full-depth avalanche occurrences. Linear regression yields $r^{2}=0.97$ for a four-event sample of rainon-snow-triggered full-depth avalanches (significant but not highly significant to 0.05 level; $t=5.64$ with two degrees of freedom). Our results indicate that the relationship between snow glide and avalanches is less predictable.
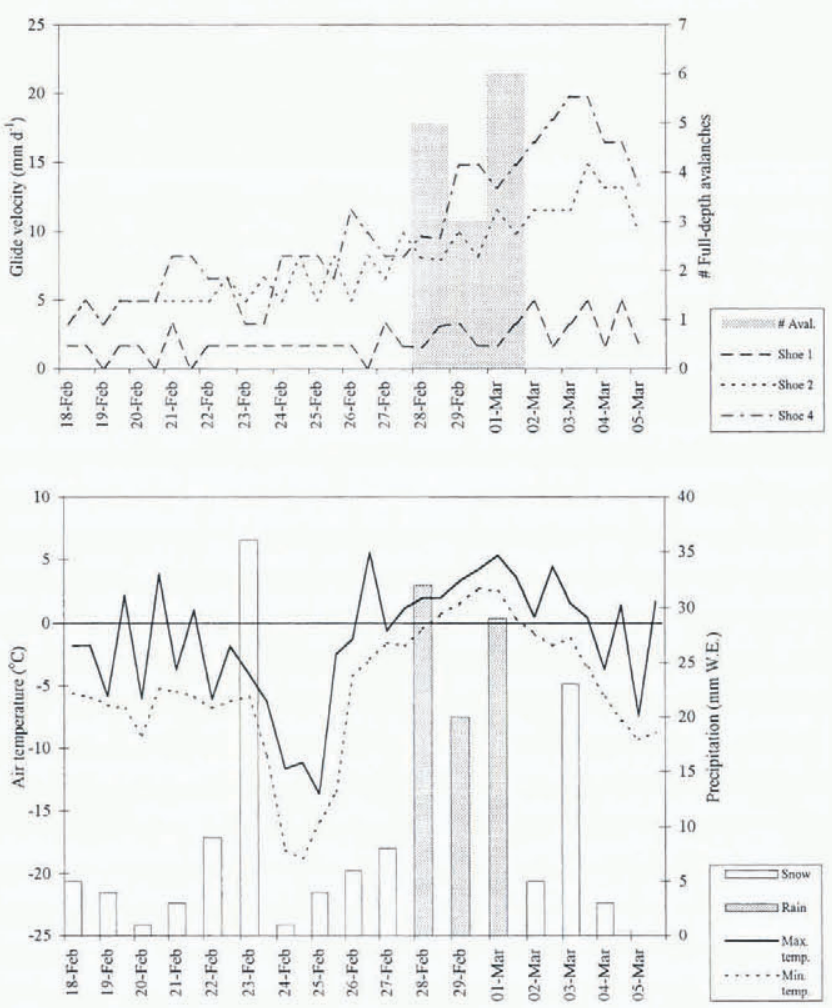

Fig. 9. Full-depth avalanche release by rain-on-snow, 18 February-6 March 1994.
If peaks in glide velocity are attributed directly to inputs of free water to the snowpack adjacent to bare rock surfaces then a general time lag can be determined. The instrumented glide site is located approximately $350 \mathrm{~m}$ downslope from an area of steeply sloped bare rock (i.e. an avalanche initiation zone). Approximate flow speeds of water at the snow/ground interface were determined in the field and were found to vary from 0.2 to $0.7 \mathrm{~cm} \mathrm{~s}^{-1}$ (Clarke, 1994). These flow speeds correspond to lag times of 14-48 hours. This may be a partial explanation for the delay in peak rates detected at the glide site.

\section{CORRELATION OF FULL-DEPTH AVALANCHE OCGURRENGE AND SNOWMELT EVENTS}

The exposure of south-facing, steep bedrock slabs on the upper slopes of Zopkios Ridge to solar radiation may enhance snowmelt. The snow cover on the ridge varies so that even during mid-winter large areas of dark-coloured rock are exposed. In areas of thin snow cover, the rock is warmed by absorbed shortwave radiation, and snow is melted by emitted longwave radiation.

Observations during two field seasons indicate that most avalanches, unless triggered by rainfall, were caused by the input of free water from snowmelt. Most (11 out of 15 in 1992-93 and 18 out of 21 in 1993-94; see Table 1) full-depth avalanches triggered by snowmelt are likely to have been triggered by snowmelt generated by warm (i.e. air temperature $>0^{\circ} \mathrm{C}$ ) periods. The remaining group of full-depth avalanches (four in 1992-93 and three in 1993-94) that released during clear, cold, calm conditions may have been the result of snowmelt by radiative heating of rock surfaces. Full-depth avalanches have been observed at temperatures as low as $-11^{\circ} \mathrm{C}$ in the Canadian Rockies (personal communication from B. Allen, 1997).

\subsection{Warm-temperature snowmelt events}

The relationship during spring between higher air temperatures and loose spring avalanches is well recognized. That between higher air temperatures and full- depth avalanches is not as well understood. Turbulent energy fluxes are difficult to instrument in remote alpine environments. The sensible-heat flux can be modeled as $Q^{*} \Delta T$, where $Q^{*}$ is net radiation and where $\Delta T=\left(T_{\text {air }}-T_{\text {surface }}\right)$ is easily measured and is used as an indicator of snowmelt.

Cross-correlation analyses between snow-glide velocity and air temperature measured at the glide site during selected time periods show that higher air temperatures relate to higher glide rates. The relationship is statistically significant and positive with lag times of 12-24 hours (Table 5). This indicates that changes in snow-glide velocity lag 12-24 hours behind changes in air temperature at our site. Results show that correlation between snow glide and air temperature is higher during snowmelt-triggered avalanche events than during rain-on-snow events.

Figure 10 illustrates conditions between 23 January and 6 February 1993. On 30-31 January, 11 full-depth avalanches were triggered by rapid snowmelt, as indicated by the above-freezing temperatures. During this period, maximum air temperatures at the study site reached $18^{\circ} \mathrm{C}$.

\subsection{Cold-temperature events}

Cold-temperature events are defined as full-depth ava- 
Table 5. Correlation of glide velocity with maximum air temperatures for selected time periods

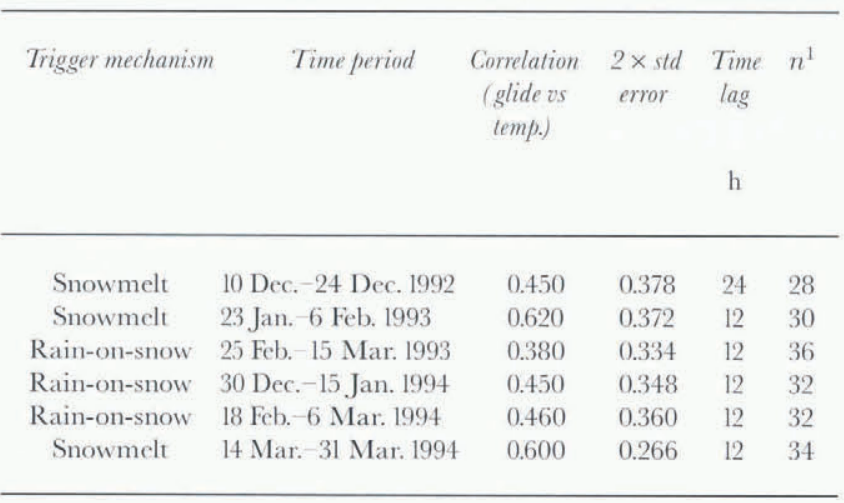

${ }^{1}$ Number of 12 hour time periods used in analysis.

lanches that occur when air temperatures are below freezing and there has not been any form of precipitation. Coldtemperature events, although uncommon, are important because they are the most difficult to predict. The release of full-depth avalanches at times when air temperatures are below freezing may be explained by the presence of meltwater at the snow/ground interface.

If the snowpack is thick enough, air temperatures will not affect temperatures at the base of the snowpack. Observations at our study site indicate that meltwater may exist at the base of the snowpack at any time regardless of air temperatures. Bare rock surfaces or a thin snowpack upslope of avalanche initiation zones may affect the presence of water at the base of the snowpack. Rock surfaces may warm on clear days despite cold air temperatures.

An example of a cold-temperature event is illustrated in Figure 11 for 10-24 December 1992. Despite below-freezing air temperatures, glide rates increase prior to the avalanche
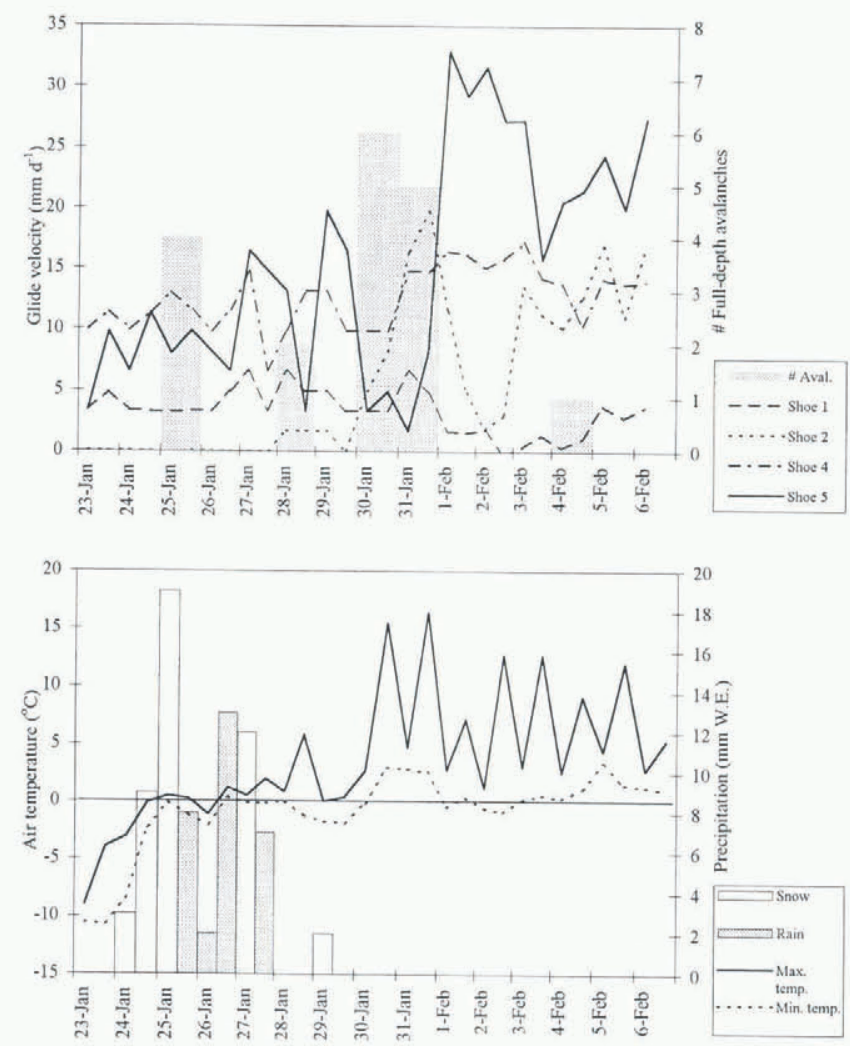

Fig. 10. Full-depth avalanche release by snowmell, 23 January6 February 1993.
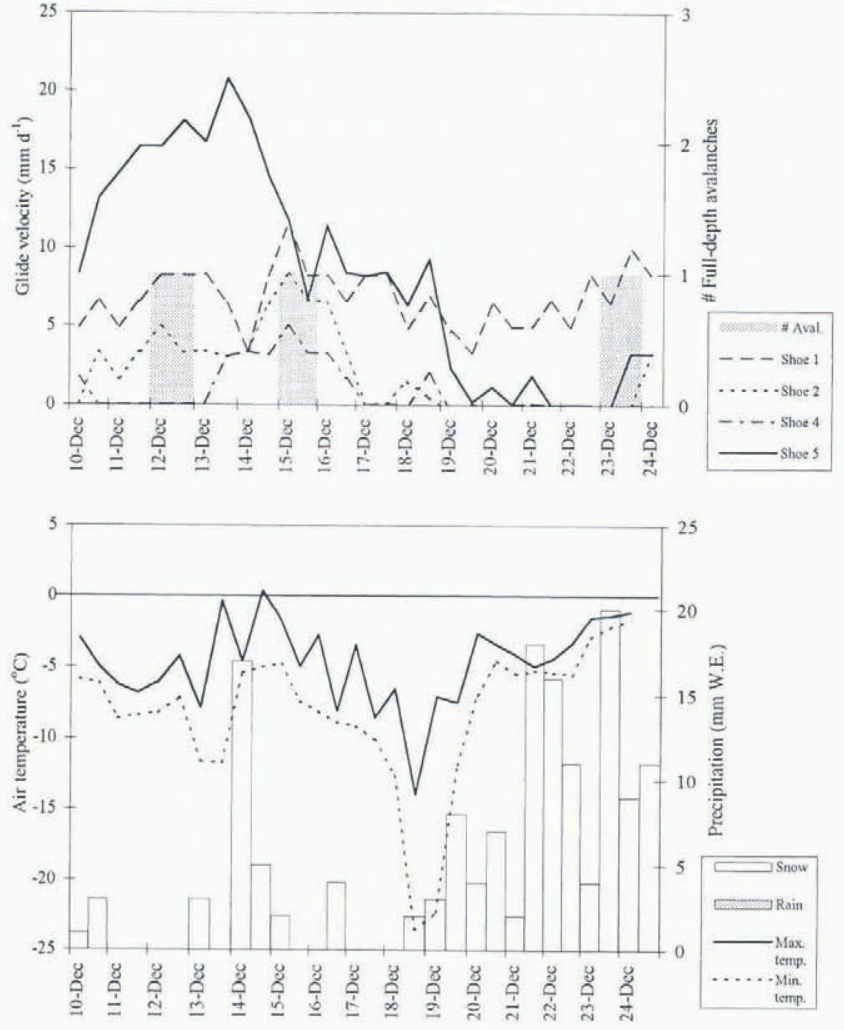

Fig. 11. Full-depth avalanche release during cold temperatures, 10-24 December 1992.

on 12 December and peak 24 hours after release. Peaks in glide rates at shoes 1,2 and 4 correspond with avalanche release on 15 December. Warming of rock slabs at the top of the path during clear sky conditions on 11 and 12 December may have had a significant warming effect on a thin snowpack. Radiation measurements from a nearby site were not reliable enough to include in this analysis due to problems associated with remote winter instrumentation.

\section{DISGUSSION AND CONCLUSIONS}

The smooth, steeply sloped and south-facing bedrock exposures, combined with moist snowpack conditions, create favorable conditions for snow glide and full-depth avalanche release at the study site. These factors provide a unique opportunity to further understand conditions associated with full-depth avalanche release.

Results from this study expand current understanding of snow glide in relation to avalanche release. We examined rates of snow glide, climate conditions and avalanche occurrence observations on a continuous time-scale over two seasons.

Results confirm that the supply of free water to a relatively smooth snow/ground interface is the principal mechanism controlling snow glide and full-depth avalanche release. The existence of a stiff layer sitting above a soft slushy film may influence the mechanics of glide in that the thickness of the weak film may limit the degree of ground roughness that can be moved across. If amplitudes of ground roughness are greater than the thickness of the slush layer, there may be a greater resistance to glide.

Evidence from two seasons of data shows that full-depth avalanches are primarily associated with rain-on-snow or snowmelt events. The results indicate that one-half to three-quarters of all avalanche occurrences in the study 
area can be attributed to rainfall events. Full-depth avalanche occurrence is positively correlated with rainfall 12 24 hours after rain-on-snow events. Observations also indicate that avalanche response is larger and quicker with higher-intensity rainfall.

Snowmelt by warm air temperatures explains almost all the other full-depth avalanches occurring in the study area. The results show that peak glide velocities lag 12-24 hours behind air temperature. Avalanches rarely occur on clear cold days. In these cases, snowmelt by radiation, especially on thin snowpacks adjacent to bare rock surfaces, may contribute sufficient quantities of meltwater to affect stability at the snow/ground interface.

The input volume and areal distribution of water from rainfall is generally larger than that from snowmelt. The location of glide instrumentation in relation to Zopkios Ridge may explain why glide rates are not as responsive to snowmelt as they are to rainfall, since the starting locations for avalanches are near the top of the path and glide rates are measured further downslope. We suspect it takes longer for meltwater to travel to the study site from upslope areas than it does for rain to infiltrate the snowpack at the glide site.

Placement of snow-glide instrumentation on a slope adjacent to and approximately $350 \mathrm{~m}$ downslope from avalanche initiation zones gives a fairly good representation of glide conditions, but it is also the likely reason peaks in glide velocity do not correspond exactly with times of full-depth avalanche release. Glide rates peak 24-48 hours after avalanche release. If instruments were placed directly in the start zones of avalanche paths, it is possible that peaks in glide velocity would correspond to times of release.

For a large area, encompassing several paths, snow glide is not a reliable indicator of full-depth avalanche release. Use of an indicator slope is, therefore, not an appropriate approach. The results of our study indicate that meteorological conditions, particularly conditions that produce free water, can be used with reasonable confidence to forecast full-depth avalanche events.

\section{ACKNOWLEDGEMENTS}

We wish to acknowledge B. Golley of MOTH for helping with data collection and the provision of snow, avalanche and weather data. This research was supported by the Natural Sciences and Engineering Research Council of Canada. Thanks also to the referees for their patient and careful review.

\section{REFERENCES}

British Columbia. Ministry of Environment. 1985. Snow survey measurements: summary 1935-1985. Victoria, B.C., Province of British Columbia. Ministry of Environment. Water Management Branch. Hydrology Section.

Clarke, J. A. 1994. Snow glide and full-depth avalanche occurrence, Cascade Mountains, British Columbia. (M.Sc. thesis, University of British Columbia.

Colbeck, S. C. and 7 others. 1990. The international classification for seasonal snow on the ground. Wallingford, Oxon, International Association of Scientific Hydrology. International Commission on Snow and Ice.

Denoth, A. 1994. An electronic device for long-term snow wetness recording. Ann. Glaciol., 19, 104-106.

Endo, Y. 1983. [Glide processes of a snow cover as a release mechanism of an avalanche slope covered with bamboo bushes.] Low Temp. Sci., Ser. A 42, 39 - 68. [In Japanese.]

In der Gand, H. R. and M. Zupančic. 1966. Snow gliding and avalanches. International Association of Scientific Hydrology Publication 69 (Symposium at Davos 1965 - Scientific Aspects of Snow and Ice Avalanches), 230- 242.

Lackinger, B. 1987. Stability and fracture of the snow pack for glide avalanches. International Association of Hydrological Sciences Publication 162 (Symposium at Davos 1986 - Avalanche Formation, Movement and Effects), $229-240$.

Lliboutry, L. 1968. General theory of subglacial cavitation and sliding of temperate glaciers. J. Glaciol., 7 (49), $21-58$.

McClung, D. M. 1975. Creep and the snow-earth interface condition in the seasonal alpine snow pack. International Association of Hydrological Sciences Publication 114 (Symposium at Grindelwald 1974 - Snow Mechanics), 236-248.

McClung, D. M. 1981. A physical theory of snow sliding. Can. Geotech. J., 18(1), 86-94.

McClung, D. M. 1987. Mechanics of snow slab failure from a geotechnical perspective. International Association of Hydrological Sciences Publication 162 (Symposium at Davos 1986 - Avalanche Formation, Movement and Effects ), 475-508.

McClung, D. M. and G. K. C. Clarke. 1987. The effects of free water on snow gliding. 7. Geophys. Res., 92 (7), 6301-6309.

McClung, D. M. and P. A. Schaerer. 1993. The avalanche handbook. Seattle, WA, The Mountaineers.

McClung, D. M., S. Walker and W. Golley. 1994. Characteristics of snow gliding on rock. Ann. Glaciol., 19, 97-103.

Nye, J. F. 1969. A calculation on the sliding of ice over a wavy surface using a Newtonian viscous approximation. Proc. R. Soc. London, Ser. A, 315(1522), $381-403$.

Yamada, Y., Y. Nohguchi and T. Ikarashi. 1991. Snow avalanche release due to instability of snow glide motion. In Japan-US Workshop on Snow Avalanche, Landslide, Debris Flow Prediction and Control, September 30-October 2, 1991, Tsukuba, Japan. Proceedings. Japanese Science and Technology Agency, 105-114. 